\title{
Modernização administrativa em contexto subnacional: estudo de caso do Detran-SP
}

\author{
Administrative Modernization in a Subnational Context: Case Study of Detran-SP \\ Modernización Administrativa en Contexto Subnacional: Estudio de Caso del Detran-SP
}

Resumo: Como em outras experiências anteriores de reforma do Estado, a implantação da Nova Administração Pública (NAP) no Brasil se deu de forma mais evidente em nível federal, sendo menos estudada no âmbito subnacional (estados e municípios). Ademais, em geral, a NAP costuma ser discutida por um ponto de vista macro, que considera a administração pública como um todo, sendo menos frequente seu estudo em nível organizacional. Assim, o objetivo deste artigo é analisar, por meio de um estudo de caso, a implantação de valores e práticas da NAP em uma organização estadual, historicamente associada às características e aos desvios da burocracia tradicional. A organização estudada é o Departamento Estadual de Trânsito de São Paulo (Detran-SP), que passou por um processo de restruturação e pode ser visto como um laboratório para entender as variáveis e desafios mais relevantes da NAP em nível subnacional, no Brasil.

Palavras-chave: Nova Administração Pública, métodos e técnicas de gestão, modernização administrativa

Dênis Alves Rodrigues - denrogp@gmail.com

Universidade de São Paulo, Escola de Artes Ciências e Humanidades, São Paulo, SP, Brasil.

Martin Jayo- martin.jayo@usp.br

Professor da Universidade de São Paulo, Escola de Artes Ciências e Humanidades, São Paulo, SP, Brasil.

Artigo submetido no dia 08-10-2015 e aprovado em 12-02-2016.

DOI: http://dx.doi.org/10.12660/cgpc.v21n68.56904 
Abstract: Like other State reforms in Brazil, the advent of New Public Management (NPM) took place more clearly at the federal level, but is less often discussed at the subnational (states and municipalities) level. Moreover, NPM [?] is generally discussed from a macro point of view, taking into consideration public administration as a whole, and is less frequently studied at the organizational level of analysis. The aim of this paper is to study, by way of a case study, the introduction of the values and practices of New Public Management in a state-level Brazilian public agency, which is historically associated with traditional bureaucratic procedures and vices. The agency studied is the São Paulo State Traffic Department (Detran-SP), which, having recently undergone a restructuring process, can be seen as a laboratory for understanding the most relevant NPM variables and challenges at the Brazilian subnational level.

Keywords: New Public Management, management methods and techniques, administrative modernization

Resumen: Como en otras experiencias anteriores de reforma del Estado en Brasil, la implantación de la Nueva Administración Pública (NAP) se ha dado de forma más evidente a nivel federal, y es menos estudiada a nivel subnacional (estados y municipios). Además, suele ser discutida en general desde un punto de vista macro, que considera la administración pública en su totalidad, y menos frecuente su estudio a nivel organizacional. El objetivo de este artículo es analizar, a través de un estudio de caso, la implantación de valores y prácticas de la NAP en una organización de nivel estadual, históricamente asociada a las características y desvíos de la burocracia tradicional. La organización estudiada es el Departamento Estadual de Tránsito de São Paulo (Detran-SP), que pasó por un proceso de restructuración y puede verse como un laboratorio para entender las variables y retos más relevantes de la NAP en nivel subnacional, en Brasil.

Palabras clave: Nueva Administración Pública, métodos y técnicas de administración, modernización administrativa

\section{Introdução}

Ao longo dos últimos 80 anos, diversas foram as experiências de modernização administrativa empreendidas pelo Estado brasileiro, com destaque para a reforma burocrática da década de 1930, para o Decreto-lei 200, de 1967 e, finalmente, para a reforma gerencialista iniciada em 1995, que introduziu no Brasil os preceitos da chamada Nova Administração Pública (NAP). Embora distintas e espaçadas no tempo, essas experiências tiveram como característica comum o fato de terem se dado com mais ênfase no plano federal e com influências mais limitadas, embora existentes, nas administrações públicas de nível subnacional. Estados e municípios foram menos privilegiados por esses projetos de modernização e, como consequência, costumam ser objeto menos frequente de discussões ou estu- dos sobre reforma do Estado no Brasil. Como contribuição a esse debate, este trabalho se propõe a estudar uma experiência recente de reforma administrativa em nível estadual.

Além disso, os estudos disponíveis sobre reforma do Estado costumam adotar um nível de análise macro, ou seja, voltado à administração pública como um todo, concedendo menos atenção ao plano interno das organizações públicas. Este trabalho pretende adotar um foco intraorganizacional, voltado a analisar como o discurso, as teorias e as ações da modernização administrativa repercutem na gestão interna das organizações públicas.

O objetivo do trabalho é analisar, a partir de um caso concreto e relevante, como a agenda de modernização administrativa da NAP, vigente no plano nacional desde a década 
de 1990, vem sendo assimilada, na prática, na gestão de organizações públicas de nível subnacional. A organização a ser estudada é o Departamento Estadual de Trânsito do Estado de São Paulo (Detran-SP), e a análise se valerá do método de estudo de caso.

Para a consecução desse objetivo, este estudo se organiza como segue. A seção 2 fornece uma revisão de literatura sobre a agenda de reformas da Nova Administração Pública (NAP), identificando os mais relevantes princípios e instrumentos que fazem parte de sua agenda. A seção 3 trata dos procedimentos metodológicos, justificando a escolha do caso e detalhando os procedimentos de coleta e análise de dados. A análise propriamente dita, valendo-se das categorias (princípios e instrumentos) identificadas na seção 2, é feita na seção 4 . A quinta comenta os achados da pesquisa e encerra o trabalho com observações sobre as limitações do estudo e sugestões para pesquisa futura.

\section{Revisão de literatura: modernização administrativa no Brasil e novos valores para as organizações públicas}

Após a redemocratização da década de 1980, e com o aumento das atribuições sociais do Estado trazido pela Constituição Federal de 1988, fortaleceu-se o entendimento de que o modelo burocrático, independentemente de seu grau de implantação no Brasil, mostrava-se inadequado. Empreendeu-se assim uma experiência de reforma voltada a superar a estrutura burocrática. Tal restruturação entra para a agenda pública com o Plano Diretor da Reforma do Aparelho do Estado - PDRAE (Brasil, 1995), que, entre seus principais objetivos, propunha sanear as contas públicas e tornar o Estado gerencial, por meio de práticas que já vinham sendo discutidas e implementadas em âmbito internacional. Essa reforma, conhecida como "Reforma Bresser", representa a chegada das práticas e valores da NAP para a gestão pública brasileira. Sua manifestação se deu inicialmente restrita ao nível federal, mas, com o tempo, iniciativas de modernização também se manifestaram, embora mais pontualmente, no plano subnacional (estados e municípios).

Na transição entre as décadas de 1990 e 2000 - nos primeiros anos, portanto, de implementação da reforma gerencial no Brasil -, Farah $(1997,2000)$ chegou a analisar diversas experiências, então recentes, de inovação na gestão pública em estados e municípios. Para a autora, essas experiências indicavam um cenário otimista, por serem vistas como tendência de evolução da gestão pública subnacional, em um contexto de crise do modelo burocrático e do Estado nacional-desenvolvimentista, com o poder local funcionando como espaço de inovação. Isso sugeria que haveria um processo incremental de modernização da gestão, que levaria à ampliação da cidadania com a democratização de processos decisórios e com melhoras no acesso a serviços públicos.

Com o passar do tempo, contudo, e quando o foco recai de forma específica sobre as reformas explicitamente baseadas nos princípios da NAP, esse otimismo inicial se vê diminuído. Entre os estudos disponíveis sobre as iniciativas de modernização explicitamente fundamentadas na NAP em nível subnacional, são frequentes os relatos de relativo malogro. Sano e Abrucio (2008), por exem- 
plo, ao analisarem o esforço de implantação de princípios da NAP no campo da saúde no estado de São Paulo, mostram que os resultados ficaram aquém do prometido, ao terem mantido inalterado o insulamento do poder executivo estadual e a baixa capacidade de controle institucional e social sobre ele. Queiroz e Ckagnazaroff (2010), por sua vez, ao analisarem a reforma denominada "Choque de Gestão" promovida a partir de 2003 pelo governo do estado de Minas Gerais, avaliam que ela conseguiu inovar em alguns aspectos importantes de mudança organizacional (estratégico, tecnológico, de controle), mas não logrou êxito em outros (humano, cultural e político).

Esses frequentes diagnósticos de insucesso ou de sucesso apenas parcial, entre os quais poderíamos incluir também o de Prado e Chasin (2011), sobre a implantação do programa Poupatempo em São Paulo, o de Fernandes et al. (2015), sobre a modernização administrativa do estado do Piauí, ou ainda o de Bianco et al. (2014), sobre projeto de modernização da Secretaria de Estado da Segurança Pública e Defesa Social do Espírito Santo (SESP), indicam a importância de se desenvolver conhecimentos sobre os avanços e, principalmente, sobre as dificuldades enfrentadas por experiências de modernização inspiradas pela NAP em organizações públicas de nível subnacional.

A questão se articula com uma onda crescente de análises críticas - que não temos a pretensão de resenhar aqui -, que têm questionado os pressupostos e ferramentas da NAP de maneira geral. À medida que experiências de reforma amadurecem e seus efeitos sobre a sociedade se tornam mais claros, um número crescente de estudos teóricos e empíricos tem apontado falhas nessa vertente administrativa e apresentado críticas a seu funcionamento (Hood e Peters, 2004; Dunleavy et al., 2006; Paes de Paula, 2005, Mongkol, 2011).

Nesse espírito, uma análise dos avanços conseguidos e dificuldades enfrentadas pela reforma baseada na NAP no Detran-SP, um caso ainda não estudado na literatura, pode ajudar a desenvolver conhecimento sobre a questão. Como ponto de partida para tanto, uma revisão de literatura sobre as propostas da NAP nos permite identificar três grandes princípios que, no âmbito dessa vertente administrativa, norteiam as ações das organizações públicas. São eles: (a) foco no cidadão, (b) eficiência; (c) transparência. A tradução desses princípios em ações por parte das organizações públicas, por sua vez, passa pela mobilização de quatro instrumentos: (i) tecnologias de informação e comunicação (TIC), (ii) gestão de pessoas, (iii) novas estruturas organizacionais, (iv) controle de resultados.

Essas sete categorias (três princípios e quatro instrumentos) são comentadas a seguir, para mais adiante servirem de lente conceitual para a análise dos sucessos e falhas da sua implementação no caso Detran-SP.

\subsection{Princípio 1: foco no cidadão}

Um dos pontos centrais da NAP é o cidadão, especialmente no que diz respeito à forma como o Estado se apresenta a ele e procura atender a suas expectativas e necessidades como usuário de serviços públicos. Melhorar o relacionamento com o cidadão, entendido dessa forma, exige muitas vezes uma restruturação da própria organização pública, que, 
em sua estrutura tradicional/burocrática, não consegue mais corresponder às necessidades: "Em todo o mundo, os cidadãos reclamam de filas intermináveis, de atendimento descortês, de regras arbitrárias, de papelada, de questionários invasivos e até, ocasionalmente, de ter de subornar um funcionário para receber serviços aos quais têm pleno direito" (Kettl, 2006, p. 81).

O modelo burocrático de gestão costuma ser criticado por sua característica estadocêntrica, ou seja, por seu modo de funcionar ser voltado para resolver os problemas do próprio Estado. À medida que o Estado passa a prestar cada vez mais serviços aos cidadãos, a burocracia voltada a si mesma torna-se um obstáculo. Num estado com características gerenciais, "o foco da atividade das organizações governamentais deve ser atender às necessidades dos cidadãos, não à conveniência dos burocratas" (Kettl, 2006, p. 81). O estabelecimento de melhores vias de relacionamento entre Estado e cidadãos não só permite o melhor acesso aos serviços prestados, como também sua evolução para accountability, ao permitir que reclamações, denúncias e sugestões sejam feitas pelos cidadãos, que são os que têm informações sobre a qualidade dos serviços prestados (Przeworski, 2006, p. 58). Sua implantação nas organizações públicas, contudo, naturalmente demanda a criação de uma cultura que permeie os processos de trabaIho, permitindo que a sociedade não apenas seja bem atendida, mas também participe dos processos de decisão (Osborne e Gaebler, 1998).

\subsection{Princípio 2: eficiência}

A questão financeira e orçamentária foi um dos principais focos de atenção do governo brasileiro durante a década de 1990. Com o objetivo de equilibrar as contas do Estado, procurou-se criar regras para a utilização de dinheiro público, a exemplo da lei de licitações (Lei Federal 8.666/1993) ou da lei de responsabilidade fiscal (Lei Complementar 101/2000), esta última já na vigência da Reforma do Estado iniciada em 1995. Além disso, os conceitos de eficiência, eficácia e efetividade se tornaram chaves para impulsionar o Estado em busca de melhores resultados.

Embora alguns países tenham instituído controles direcionados ao resultado de programas e políticas (Pollitt e Bouckaert, 2011), no Brasil, o que se verificou foi a intensificação do controle orçamentário e financeiro, materializado, por exemplo, na criação do Planejamento Plurianual (PPA): vinculou-se o orçamento a programas e projetos, o que garantiu maior controle dos gastos públicos. "Fazer mais por menos" tornou-se palavra de ordem para os administradores públicos, e medidas de eficiência e eficácia foram associadas à racionalidade dos processos e à redução de custos.

\subsection{Princípio 3: transparência}

Preocupações com transparência e prestação de contas têm aumentado consideravelmente em diversos contextos nacionais de reforma administrativa, como destacam Pollitt e Bouckaert (2011, p. 110). No caso brasileiro, a questão está na pauta das transformações do setor púbico até mesmo por força de lei, haja vista a Lei 12.527/2011, conhecida como Lei de Acesso à Informação, que estabelece o princípio da transparência ativa: os órgãos públicos têm a obrigação 
de publicar um conjunto mínimo de informações de interesse público, não bastando apenas responder a pedidos de informação.

A transparência, ademais, não envolve apenas disponibilizar informações ao cidadão, mas também evitar que ele se perca na burocracia ao ter acesso a serviços e incorra em prejuízos financeiros ou de tempo. Um importante item relacionado à transparência, por ambos esses ângulos, é a necessidade de investimentos em tecnologias de comunicação e informação (TIC), que permitam melhor interação entre cidadãos e Estado, o que levaria a uma melhora em termos democráticos (O’Donnell, 2011).

Outro ponto que merece atenção são as potencialidades, ainda não totalmente exploradas, de utilização de ferramentas de Tecnologias da informação e comunicação (TIC), visando à ampliação de mecanismos de participação social. Abrucio (2007, p. 77) reforça que "o ponto em que houve menor avanço do governo eletrônico é exatamente na maior interatividade com os cidadãos", em que pese a abundante oferta de novas ferramentas tecnológicas à disposição.

As novas ferramentas de TIC podem auxiliar no maior controle da burocracia, a partir do fortalecimento das Ouvidorias e demais canais pelos quais o cidadão possa obter informações (transparência), bem como de reclamar e sugerir (accountability).

Um dos limites da utilização de TIC em favor da transparência e governança democrática tem sido, conforme Colombo (2006), a estratificação digital (desigualdade no acesso à tecnologia por parte da população): embora as TIC possam ser uma forma de impulsionar a transparência e governança democráticas, ainda assim é necessário criar políticas públicas para que a maior parte da população tenha acesso a elas.

\subsection{Instrumento 1: tecnologias de informa- ção e comunicação (TIC)}

As TIC constituem um instrumento importante, dentro da NAP, na decisão de ter, como foco, o cliente e a transparência. Complementando essa visão, Kettl (2006, p. 84) reforça a importância de se fazer uso dessas tecnologias para um:

redesenho radical dos procedimentos de trabalho, com vistas a assegurar que usuários ou consumidores encontrem o que procuram. Muito frequentemente esse processo (redesenho dos processos de trabalho) é complementado por mudanças profundas na estrutura organizacional (...) e por investimentos em novas tecnologias de informação.

Nesse contexto de restruturação administrativa, as TIC proporcionam automatização dos processos, com ganhos de tempo e eficiência, o que também proporciona melhor aproveitamento dos recursos humanos, liberando mão de obra para outras atividades. Não obstante, muitas vezes resulta difícil separar ações que são especificamente automatizações de processo de ações que permitem, também, transparência e accountability. Cunha e Miranda (2013) chamam a atenção para o fato de a fronteira entre aplicações de TIC voltadas a e-administração, e-serviços e e-democracia (expressões usadas pelos autores para designar o uso de tecnologia em diferentes dimensões da gestão pública) é difícil de delimitar. Alinhado com esse 
discurso, Abrucio (2007, p. 77) afirma que "a tecnologia de informação tem levado à redução dos custos, bem como ao aumento da transparência nas compras governamentais, reduzindo o potencial de corrupção," o que sugere o potencial extremamente importante das TIC, ora como catalizadora de eficiência, ora como forma de atingir a transparência de um processo crítico.

Uma crítica que costuma ser feita, contudo, aos primeiros investimentos em TIC na área pública é que foram pautados muitas vezes pela lógica burocrática, ou seja, buscavam maior eficiência e controle da burocracia. Com isso, os órgãos públicos brasileiros dispõem de um conjunto de sistemas "comprometidos com o usuário-burocrata, ao invés do usuário-cidadão" (Saur, 2001, p. 6). Nesse sentido, para cumprirem seu potencial dentro da NAP, as TIC precisam vir acompanhadas da reformulação administrativa dos órgãos e organizações públicas a fim de quebrar sua tradicional lógica estadocêntrica.

De outro lado, também verificamos experiências bem-sucedidas relacionando TIC e melhoras no atendimento ao cidadão, associadas à restruturação administrativa e à revisão de processos. Como exemplo, é possível citar a experiência do programa Poupatempo, no estado de São Paulo. Temos aqui um caso em que, ampliando seu foco para além da eficiência, as TIC possibilitaram outras ações - voltadas ao bom atendimento e à integração de processos - com ampla aprovação popular. Nessa seara, podemos verificar que o emprego de TIC possibilitou que a administração pública se modernizasse, permitindo melhoras de eficiência e de atendimento ao cidadão.
Trata-se de um uso de tecnologia coerente como preconizado por Fresneda (1998, p. 72), para quem "a Tecnologia da Informação é o suporte para o uso efetivo e eficiente do recurso informação, e adicionalmente, pode ser utilizada como um fator decisivo na propulsão do processo de transformação de uma instituição pública".

\subsection{Instrumento 2: gestão de pessoas}

Para que se possa praticar o princípio de melhorar o atendimento ao cidadão, um dos pontos principais a serem trabalhados é justamente o funcionário que fará esse atendimento ou que, de alguma forma, participará desse processo. É de se esperar que organizações afinadas com o princípio do foco no cidadão procurem atingir esse objetivo a partir do desenvolvimento e valorização de seus quadros. Como expressam Osborne e Gaebler (1998, p. 300), elas "pagam bem a seus funcionários e se esforçam no sentido de melhorar a qualidade de seus ambientes de trabalho. Além disso, investem em treinamento". Nesse aspecto, não apenas a questão salarial está envolvida, mas a preocupação com o ambiente de trabalho, treinamento e participação dos funcionários, isto é, envolvimento desses nos processos decisórios. Por esse motivo, a organização se afasta de um modelo de gestão top down e procura melhorar o desenvolvimento organizacional e investir em recursos humanos.

Para que a organização consiga motivar seus funcionários, os exemplos precisam vir dos dirigentes, aos quais cabem promover essa nova cultura, estimulando os valores desejados e o comportamento esperado dos funcionários (Osborne e Gaebler, 1998). Ainda, Denhardt (2012, p. 130), de forma ali- 
nhada com o humanismo organizacional, ressalta que:

estudos científicos sobre o comportamento do trabalhador e a organização informal levaram à conclusão de que estilos mais abertos e participativos de administração resultaram não só em trabalhadores mais satisfeitos, mas também em trabalhadores mais produtivos.

Bonificações por resultados, atrelando parte da remuneração dos funcionários a seu desempenho, são medidas adotadas em diversos países que têm modernizado sua gestão pública a partir dos princípios da NAP (Pollitt e Boukaert, 2011). No caso específico do Brasil, é possível verificar algumas experiências que tentam se aproximar disso, com avaliações de desempenho e bonificação por resultado - caso, por exemplo do Estado de São Paulo, por meio da Lei Complementar 1079/2008. Apesar disso, o que tem preponderado são os aumentos salariais focados em qualificação e antiguidade (gratificações por quinquênio, sexta parte etc.).

\subsection{Instrumento 3: novas estruturas organi-} zacionais

A forma como são estruturadas as organizações públicas não ficam ilesa às mudanças trazidas pela NAP. Fazem-se necessárias mudanças organizacionais que propiciem maior agilidade, bem como diminuição da complexidade burocrática na implementação de ações estratégicas (Xavier e Dias, 2002).

Analisando o histórico de reformas no setor público brasileiro, entretanto, diversos autores registram problemas na forma como a mudança organizacional costuma ser conduzida. Wood Jr. et al. (1992), por exemplo, observa que as mudanças em cargos, órgãos e procedimentos costumam em geral ser promovidas com uma visão mecanicista, isto é, sem levar em conta aspectos comportamentais relacionados ao aspecto humano da mudança. Outro problema diz respeito a questões de continuidade e descontinuidade administrativa: cada governante se vê tentado a introduzir muitas dessas mudanças, "reinventando" o aparelho do Estado com o propósito de demarcar a nova administração, de acordo com propósitos políticos (Chaves \& Marques, 2006; Beatriz \& Machado-da-Silva, 1999).

Isso contrasta com a necessidade de mudança organizacional defendida pelos teóricos da NAP. Para Pollitt e Boukaert (2011), as organizações públicas têm seu funcionamento afetado pela NAP em diferentes dimensões: especialização, coordenação, centralização/ descentralização e escala. Os autores ainda ressaltam que as organizações públicas têm se apropriado de práticas do mercado, aproximando suas práticas e estruturas organizacionais daquelas existentes no setor privado.

Quanto à especialização, os autores ressaltam a importância de que organizações públicas tenham uma atividade específica (especializada), retirando funções que disputem entre si ou sejam conflitantes, todavia, isso pode resultar no aumento do número de organizações públicas.

No que tange à coordenação, sublinham a necessidade de que orientações da cúpula da organização fluam com agilidade às demais diretorias e, quando cabível, às filiais 
ou unidades regionais, mantendo coerência no trabalho e orientação única no órgão. Isso pode envolver, muitas vezes, uma simplificação do organograma, com redução do número de níveis hierárquicos.

A descentralização, desde que associada a mecanismos de coordenação, parece ser uma das formas de se obter melhor atendimento à população, uma vez que uma estrutura decisória centralizada com pouco conhecimento da realidade da população "na ponta" pode trazer distorções e erros nas decisões e orientações.

Finalmente, as características relacionadas à escala das organizações públicas são, para Pollitt e Boukaert (2011, p. 104), decorrência das dimensões anteriores: a organização pública ideal, no contexto da NAP, será em geral achatada (flat), flexível, especializada e descentralizada, e, por conseguinte, tenderá a ser também relativamente pequena. Isso configura um desafio para as organizações públicas brasileiras, já que:

na história brasileira registram-se movimentos de reforma administrativa (...) [que] não evitaram a manutenção de estruturas obsoletas, pesadas e hierarquizadas, pouco dinâmicas e excessivamente caras, sobretudo devido à tendência à centralização e à superposição de órgãos e de funções (Brasil, 1995, p. 17).

\subsection{Instrumento 4: controle de resultados}

Embora isso fique mais evidente em determinadas áreas, como a financeira, os temas abordados anteriormente pressupõem monitoramento e medição de desempenho, fundamental, por exemplo, quando falamos em controle de resultados. Neste sentido, "é claro que um controle maior de resultados tem sido um elemento central nas reformas da administração pública de diversos países" (Pollitt e Bouckaert, 2011, p. 106).

De fato, tem-se observado uma crescente melhora nas práticas de mensuração, que deixam de circunscrever-se a questões financeiras e de custos para evoluir para indicadores e análises mais completas de eficácia e efetividade, além de qualidade do atendimento. Com a NAP, há um deslocamento da mentalidade tradicional de controle burocrático de procedimentos, em direção a um controle focado nos resultados. Ainda que não se abandonem completamente os controles procedimentais (até mesmo porque em muitos países, como o Brasil, boa parte desses controles está prevista em lei), mas responde-se a uma das mais frequentes críticas ao modelo burocrático de gestão: "engessar" a máquina administrativa. Nos termos de Lima (2007, p. 90), "uma gestão pública voltada para resultados reduz ao mínimo o controle a priori e é abundante em monitoramento e avaliação".

\section{Aspectos metodológicos}

Para estruturar a parte empírica do trabalho, apresentada na seção 4, optamos pela utilização do método do estudo de caso. Em particular, desenvolvemos um estudo de caso único, nos moldes propostos por Yin (1994). Esse autor argumenta que o método do estudo de caso pode ser utilizado sem maiores limitações metodológicas, sempre que (i) a questão de pesquisa seja do tipo "como" ou "por que", isto é, voltada às relações que precisam ser acompanhadas no tempo, mais do que meras frequências ou 
incidências; (ii) o pesquisador não detenha controle sobre o evento estudado, isto é, não possa manipulá-lo ou reproduzi-lo fora do seu contexto original; (iii) o evento estudado seja contemporâneo à pesquisa. Com relação ao presente trabalho, podemos afirmar com segurança que as condições levantadas por Yin são atendidas, uma vez que: (i) a questão de pesquisa se volta a entender "como" a agenda da NAP é internalizada nas organizações públicas e "como" ela impacta a gestão dessas organizações; (ii) o objeto de pesquisa - modernização do Detran-SP - não é reprodutível fora de seu contexto; (iii) configura-se um fenômeno contemporâneo à pesquisa: a incorporação da agenda de reformas da NAP à administração pública brasileira está em curso, e os eventos estudados tiveram início em 2011.

Cumpridas essas condições de aplicabilidade, a opção pelo estudo de caso único (em oposição ao estudo de casos múltiplos) se justifica, segundo Yin (1994, p. 38-41), quando:

(a) se está diante de um caso crítico para o teste (falseamento) de uma teoria; (b) trata-se de caso peculiar, difícil de ser observado; ou (c) trata-se de um caso revelador de um fenômeno novo, previamente inacessível à investigação.

Neste estudo, o Detran-SP, por seus atributos excepcionais (é o maior Departamento Estadual de Trânsito do país e por constitui rara experiência de um fenômeno novo), a implantação de princípios e valores da NAP numa grande organização pública de nível subnacional reúne características tanto de caso peculiar como de caso revelador, justificando a opção pelo estudo de caso único.
Tanto Yin (1994) como outros autores que advogam a favor do estudo de caso único em pesquisas na área de Gestão, como Mariotto et al. (2014), ressaltam que, nesse tipo de pesquisa, é importante garantir a triangulação de dados, isto é, utilizar diferentes mecanismos de coleta, bem como uma análise confrontada dos dados dessas diversas fontes, a fim de fortalecer as conclusões que serão extraídas do caso. Nesse espírito, a pesquisa se beneficiou de diferentes estratégias de coleta de dados junto ao Detran-SP: (i) observação participante, dado o primeiro autor ter atuado profissionalmente no início do projeto de restruturação do órgão; (ii) documentos públicos relacionados à legislação de trânsito federal e estadual, normatizações, portarias etc., além do conteúdo disponível publicamente no próprio website do Detran-SP; (iii) documentos internos da instituição estudada, tais como relatórios, comunicados e pesquisas de satisfação encomendados pelo órgão, desde que não fossem confidenciais; (iv) entrevistas pessoais com dois gestores que tiveram papel chave na implementação do projeto de modernização do Detran-SP e que, portanto, detêm uma visão abrangente sobre o projeto, relacionados no Quadro 1.

As entrevistas foram semiestruturadas, com base em um roteiro mínimo, a fim de dar liberdade aos entrevistados para abordarem assuntos não antecipados e que, eventualmente, não tivessem sido detectados pela revisão de literatura apresentada na seção 2 ou por meio das demais formas de coleta.

Como roteiro mínimo para as entrevistas, utilizou-se a lista dos três princípios (foco no cidadão, eficiência e transparência) e quatro 
instrumentos (TIC, gestão de pessoas, novas estruturas organizacionais e controle de resultados) identificados na revisão de literatura, a fim de verificar, a partir da visão dos entrevistados, de que forma cada um deles se materializou, ou não, no caso Detran-SP. As entrevistas foram feitas pessoalmente, com duração aproximada de duas horas cada uma delas. Por opção do pesquisador, elas não foram gravadas, preferindo-se fazer anotações detalhadas durante e imediatamente após as entrevistas, a fim de garan- tir a espontaneidade dos relatos. A interação entre o pesquisador e os entrevistados, contudo, não se resumiu ao momento das entrevistas, uma vez que novos contatos, tanto telefônicos como por e-mail, foram feitos durante a fase de análise, a fim de checar dados, contrastar informações e esclarecer dúvidas. Tanto as entrevistas como os contatos posteriores com os entrevistados tiveram importância para a triangulação de dados, possibilitando a checagem e confirmação de informações obtidas nas demais fontes.

Quadro 1. Relação dos entrevistados

\begin{tabular}{|l|l|l|l|}
\hline Nome* $^{*}$ & Cargo & $\begin{array}{l}\text { Data da entre- } \\
\text { vista }\end{array}$ & $\begin{array}{l}\text { Vinculado órgão na } \\
\text { data da entrevista }\end{array}$ \\
\hline Daniel Annenberg & $\begin{array}{l}\text { Diretor-Presidente do De- } \\
\text { tran-SP até abril/2014 }\end{array}$ & $20 / 05 / 2014$ & Não \\
\hline Vera Viviane Schmidt & $\begin{array}{l}\text { Coordenadora adjunta } \\
\text { do Detran-SP até novem- } \\
\text { bro/2012 }\end{array}$ & $19 / 07 / 2014$ & Não \\
\hline
\end{tabular}

*Os entrevistados consentiram a publicação explícita de seus nomes.

\section{Caso}

O início das análises e propostas para a reforma do Detran-SP deu-se em 2010, embora não seja possível estabelecer uma data muito precisa. Registrada a questão na agenda pública, sua implementação passou a ocorrer de forma gradual (incremental), na velocidade que a administração pública paulista suportasse. Esse modelo de implantação é coerente com o que descreve Lindblom (2010, p. 175), para quem "não se decide uma política de uma vez por todas; ela é formulada e reformulada indefinidamente", e "as democracias modificam suas políticas quase exclusivamente mediante ajustes incrementais" (p. 172). Sintoma disso é que o Detran-SP, originalmente um órgão da administração direta (coordenadoria vinculada à Secretaria da Segurança Pública em um primeiro momento e, em seguida, à Secretaria da Gestão Pública), só depois de aproximadamente dois anos do início da reforma teve alterada sua configuração jurídica, tornando-se autarquia (órgão da administração indireta, o que lhe confere maior autonomia administrativa e financeira).

Esse modo incremental de implantar a reforma - talvez também reflexo de uma fal- 
ta de conhecimento real do problema a ser enfrentado em uma instituição tão complexa, autorreferida e pouco permeável - pode ser visto a partir dos diversos decretos que se sucederam no tempo, prorrogando o término das mudanças. O primeiro deles foi o Decreto 56.843/2011, segundo o qual a transição deveria ser feita em um prazo de seis meses, mas depois vieram os Decretos 57.736/2012, 58.205/2012, 58.836/2013, 60.030/2014 e, finalmente, o 60.365, de 15/04/2014, que concedia mais 45 dias para a transição.

Há que se notar, também, que já se verificava há algum tempo um esforço político e administrativo para melhorar o atendimento ao cidadão, com aumento de transparência e desburocratização, materializado no programa Poupatempo, implantado no estado de São Paulo em 1996. Essa ligação é tão visível que a restruturação do Detran-SP costuma ser chamada de "implantação do modelo Poupatempo," e o diretor-presidente que a levou a cabo foi o mesmo executivo que implantara esse programa anos antes.

Apesar disso, para que o processo fosse levado adiante, de acordo com Vera Viviane Schmidt, entrevistada em 19/07/2014, foi importante:

a vontade do governo estadual de realizar essas transformações e a não ingerência política no projeto. Isto fez com que o planejamento fosse realizado apenas visando aos objetivos maiores como o foco no cidadão/cliente, e a eficiência e transparência da atuação estatal.

Isso nos permite um maior aprofundamento em cada um dos três princípios e quatro instrumentos selecionados na seção 2 como categorias de análise para guiar o caso.

\subsection{Princípio 1: foco no cidadão}

Como observa Azoubel (2006, p. 51):

na área pública não basta dizer que se está priorizando o cidadão. É preciso que essa iniciativa fique muito clara para o público, através de decisões gerenciais que coloquem a área de atendimento em um razoável nível de importância dentro da organização.

Isso justifica que analisemos de que forma esse princípio foi contemplado na restruturação administrativa do Detran-SP.

Ao menos no plano discursivo, o foco do cidadão foi uma das principais bases da reforma. "Este foi um dos focos balizadores do projeto: a questão de se ter o foco na pessoa que recebe o serviço foi priorizada ao máximo ao longo dos últimos três anos", ressaltou em entrevista Daniel Annenberg, diretor-presidente do órgão que coordenou o projeto em pauta. Ademais, de acordo com a Lei Complementar 1.195/2013 e Decreto $59.055 / 2013$, na nova estrutura do Detran-SP, que se tornava uma autarquia, criou-se a Diretoria Setorial de Atendimento ao Cidadão, o que reforça a preocupação, presente no discurso da reforma, de priorizar as necessidades do cidadão.

No desdobramento desse foco em ações, isto é, na sua concretização, várias medidas foram tomadas, tais como a implementação de comunicação aos cidadãos (por meio de cartas e SMS) a fim de avisar eventos como a proximidade do vencimento da Carteira Nacional de Habilitação $(\mathrm{CNH})$ ou a permissão 
para dirigir, o atingimento de dez pontos por infrações de trânsito, entre outros - informações até então disponíveis apenas no sítio eletrônico do órgão. Isso sugere a busca de um relacionamento mais proativo com o usuário, evitando que, por esquecimento ou desinformação, ele seja sujeito a transtornos como multa e apreensão de veículos ou tenha restrições no direito de dirigir. Adicionalmente, muitos dos serviços que se desdobram da emissão dessas comunicações - como a solicitação de CNH definitiva, por exemplo - passaram a ser oferecidos pela internet. Criou-se um sítio eletrônico onde o cidadão pode ter acesso a vários serviços (segunda via de $\mathrm{CNH}, \mathrm{CNH}$ definitiva, extrato de pontuação, extrato de multas do veículo etc.), sugerindo que a modernização do órgão foi pautada por uma preocupação que engloba orientar adequadamente o cidadão e oferecer-lhe canais de serviço mais rápidos e convenientes. Necessário salientar que isso aproxima o cidadão do órgão público, evitando a necessidade de usar atravessadores, como os despachantes.

Outras medidas dignas de nota foram: (i) melhora dos locais de atendimento, instalando-se ou ampliando-se pontos de atenção ao público em estações de metrô; (ii) criação do "Disque-Detran" e do "Fale com o Detran-SP", canais voltados a resolução de dúvidas e orientação de usuários, respectivamente por telefone e pela internet, (iii) criação de perfis da instituição em redes sociais (Twitter e Facebook), entre outras. Tais ações, voltadas ao cidadão, acabaram desencadeando a necessidade de outras que se relacionam com os demais princípios e instrumentos expostos na seção 2: revisão de processos, criação de serviços eletrônicos, aumento de transparência, criação de
Ouvidoria etc.

Em março de 2014, pesquisa realizada pela Fundação Sistema Estadual de Análise de Dados (Seade, 2014) avaliou os resultados dessas medidas ao mensurar a percepção de qualidade por parte dos cidadãos atendidos pelas chamadas "Ciretrans novas" e "Ciretrans antigas". Ciretran é a sigla para Circunscrição Regional de Trânsito, que corresponde à extensão do Detran nos municípios. As Ciretrans "novas" são aquelas em que, no momento da pesquisa, estavam no novo formato de atendimento, e as "antigas" ainda mantinham o modelo anterior à transição. A pesquisa também mediu a percepção de qualidade dos cidadãos atendidos pelo Detran-SP por meio do programa Poupatempo.

O relatório, cujos resultados detalhados estão disponíveis na Seade (2014), conclui que a percepção de qualidade dos cidadãos meIhorou, porém identifica oportunidades de melhora relacionadas sobretudo à quantidade de vezes que o cidadão precisa dirigir-se a uma unidade do Detran-SP para solucionar um problema, à infraestrutura dos locais de atendimento e à postura dos funcionários. Por último, um ponto não trabalhado na restruturação é a participação: a sociedade de forma geral manteve pouca participação nas decisões do órgão, não tendo sido fomentados canais participativos de consulta.

\subsection{Princípio 2: eficiência}

Como se vê na Tabela 1, a reformulação do Detran-SP não gerou diminuição de gastos; ao contrário, para dar cabo de todos os projetos (remodelagem de locais de atendimento, implantação de canais eletrônicos etc.), 
foi necessário um incremento substancial do orçamento - situação que, à primeira vista, parece uma contradição em relação à lógica da NAP, que preconiza a necessidade de racionalização e redução de gastos. A situ- ação configura um trade off semelhante ao discutido por Pollitt e Bouckaert (2011): nem sempre é possível melhorar o desempenho de um órgão público e ao mesmo tempo diminuir seus gastos.

Tabela 1. Evolução orçamentária do Detran-SP

\begin{tabular}{lcl}
\hline Ano & Orçamento (R\$ milhões) & Secretaria vinculada \\
\hline 2008 & 123,1 & Segurança Pública \\
2009 & 214,9 & Segurança Pública \\
2010 & 274,8 & Segurança Pública \\
2011 & 303,4 & Segurança Pública \\
2012 & 570,6 & Gestão Pública \\
2013 & 549,3 & Planejamento e Desenvolvimento Regional \\
2014 & 686,6 & Planejamento e Desenvolvimento Regional \\
\hline
\end{tabular}

Fonte: Leis Orçamentárias anuais

O entrevistado Daniel Annenberg sugere que o projeto de restruturação encontrou dificuldades em relação à eficiência, em primeiro lugar por não ser o objeto principal da reforma e, em segundo, pela ausência de relatórios gerenciais que permitissem tomar decisões nesse âmbito: "Não tínhamos relatórios gerenciais. Eles são essenciais e não é adequado, cada vez que você precisa de um relatório, ter de esperar alguns dias até que ele seja gerado." Com isso, a falta informações gerencias que permitiriam encontrar oportunidades de redução de custos atuou como entrave nessa questão.

Ainda de acordo com o entrevistado "conversamos com quase todos os fornecedores do Detran-SP e, na maioria dos casos, conseguimos reduzir de 5 a 10\% os custos", porém o resultado dessa ação se manteve marginal pelo fato de muitos dos serviços contratados pelo órgão serem limitados a determinados fornecedores homologados pelo Departamento Nacional de Trânsito
(Denatran), como é o caso da emissão da $\mathrm{CNH}$, restringindo a concorrência e a possibilidade de negociação.

É certo, por outro lado, que o investimento realizado em novos canais eletrônicos de atendimento, mencionado no item anterior, tende a resultar em ganhos futuros, difíceis de quantificar, de eficiência ao substituir o atendimento presencial por formas mais econômicas de interação com o público. Com efeito oposto, vale salientar que os sistemas informatizados do Detran-SP carecem de integração, exigindo retrabalho na entrada de dados em diferentes sistemas do mesmo órgão, o que diminui sua eficiência. Este último aspecto será retomado no item 4.4.

\subsection{Princípio 3: transparência}

O princípio da transparência apresenta, em grande medida, intersecções com o de foco no cidadão. A criação de uma Ouvidoria, inexistente até a restruturação, é exemplo de 
medida que se relaciona com ambos. Daniel Annenberg ressalta que a preocupação com a transparência pautou inclusive o projeto arquitetônico das unidades de atendimento ao público, que tiveram seu layout projetado "para dar transparência na relação com o cidadão e para que ele possa perceber que o Detran-SP está abrindo todas as informações para ele".

Por outro lado, analisando o sítio eletrônico do órgão (http://www.detran.sp.gov.br), percebe-se, sem muita dificuldade, que seu conteúdo privilegia o acesso a serviços (agendamentos, solicitação de segunda via de $\mathrm{CNH}$ etc.) e a informações de cidadãos e veículos (prontuário, pesquisa de gravame, pesquisa de multas etc.), em detrimento do acesso a dados referentes ao próprio órgão. Embora seja possível encontrar ali informações sobre DPVAT (seguro obrigatório), frota de veículos e estatísticas de lacração e outras informações - como valores arrecadados por taxas e multas, contratos firmados, empresas envolvidas, número de habilitados por categoria, quantidade de provas teóricas e práticas realizadas, bem como as respectivas porcentagens de aprovados e reprovados etc. - estão ausentes. Assim, embora o sítio eletrônico seja muito bem explorado como canal de serviço, ele é subaproveitado como canal de transparência. Concluímos que, se por um lado houve preocupação com maior acesso do cidadão às suas próprias informações e às de seu veículo, por outro o Detran-SP evoluiu muito pouco quanto à transparência de suas prestações de contas, contratos e estatísticas.

\subsection{Instrumento 1: TIC}

A importância das TIC em Departamentos de Trânsito é ressaltada por Azoubel (2006, p. 37), para quem:

o volume de informações com que lidam estas instituições é enorme, e o ambiente operacional é considerado de missão crítica, pois dele depende também a operação de um número razoável de outras instituições.

Isso é válido uma vez que os órgãos municipais de trânsito, por exemplo, podem autuar condutores e, para tal, dependem dos bancos de dados dos departamentos estaduais de trânsito, em que constam os registros dos condutores e veículos.

Os esforços para tornar o atendimento menos burocratizado e mais focado no cidadão exigiram revisão de processos, e isso se deu com apoio de ferramentas de TIC, com o emprego de sistemas informatizados para gerenciar processos ou prestar serviços por meio de canais eletrônicos. Contudo, a infraestrutura de que o órgão dispunha para tanto era composta por sistemas ultrapassados, desenvolvidos há pelo menos duas décadas. Se, por um lado, novas aplicações foram desenvolvidas, por outro isso se fez sem alterar a infraestrutura legada, o que provoca ineficiências devido à ausência de integração entre sistemas.

Exemplo de um desses novos sistemas é o e-CNHsp, desenvolvido a partir de 2010 para uso em plataforma web, que hoje controla os processos de primeira habilitação, adição de categoria, renovação de $\mathrm{CNH}$ etc., e permite a fiscalização do cumprimento de aulas teóricas e práticas, bem como a consulta ao andamento do processo do cidadão por meio do sítio eletrônico do Detran-SP. Os dados 
inseridos nesses sistemas - por exemplo, aqueles preenchidos pelo cidadão, e pelos credenciados como os centros de formação de condutores (autoescolas), médicos e psicólogos -, precisam ser posteriormente transcritos para outro sistema estadual a fim de alimentar o Registro Nacional de Carteiras de Habilitação (Denatran-Renach) - trabalho que precisa ser feito para cada novo dado inserido em todos os processos. Pela mesma lógica, porém com sentido inverso, há informações que estão nos sistemas do órgão, mas não podem ser consultadas pela internet por falta de integração com 0 e-CNHsp, como o histórico de renovações de $\mathrm{CNH}$ e os eventuais cumprimentos se suspensão do direito de dirigir. Vê-se que, embora o novo sistema seja uma plataforma moderna, que possibilitou o agendamento de serviços pela internet, sua utilização em paralelo com os sistemas legados gera retrabalho e aumenta as dificuldades de administração das informações do órgão.

Um dos principais entraves para a superação dessa situação, na avaliação de Daniel Annenberg, seria a dependência em relação à Companhia de Processamento de Dados do Estado de São Paulo (Prodesp), fornecedora de tecnologia do órgão:

Infelizmente a Prodesp é um pouco lenta para responder à enorme demanda de mudanças que o Detran-SP tinha. Em determinado momento estávamos com mais de 200 demandas de melhorias de sistemas, e o fornecedor não estava dando conta.

Uma forma de resolver essas pendências teria sido a contratação, por meio de licitação, de empresas capacitadas para tais ser- viços, o que não chegou a acontecer. Uma interpretação para isso passa pela percepção da complexidade da relação comercial entre Detran-SP e Prodesp: várias das pessoas da Diretoria de Sistemas do primeiro são originalmente funcionários da segunda, o que pode causar conflitos de interesses. Essa questão ainda precisa ser resolvida.

\subsection{Instrumento 2: Gestão de pessoas}

A restruturação do Detran-SP envolveu, em grande medida, mudanças nas políticas de gestão de recursos humanos do órgão. $A$ ação mais evidente nesse sentido - embora não tenha sido a única - foi a elevação real dos salários. Por meio da Lei Complementar 1.195/2013, os mais de 2.500 oficiais administrativos do órgão receberam aumentos médios de $56 \%$ em suas remunerações. A isso se somou à criação de um programa de bonificação por resultados.

Tão importante quanto isso foi a criação das carreiras permanentes de Agente Estadual de Trânsito, com 1.400 vagas e exigência nível superior, e Oficial Estadual de Trânsito (800 vagas, nível médio), e a subsequente abertura de um concurso público, em junho/2013, para preenchimento de 1.200 dessas vagas sendo 600 de Agente e 600 de Oficial. Com isso, criou-se uma carreira própria para o Detran-SP e um corpo técnico da área de trânsito, que serão o apoio para o desenvolvimento futuro da autarquia, uma vez que, anteriormente, a mão de obra utilizada pelo órgão era composta essencialmente por policiais civis e oficiais administrativos, que não tinham atividades exclusivas de trânsito. Delegados, investigadores e demais policiais civis, vinculados ao Detran-SP, aos poucos começaram a retornar a suas atividades junto à 
secretaria estadual de Segurança Pública.

Outra ação importante, reforçada por Vera Viviane Schmidt, foi o estímulo dado a funcionários para que fizessem cursos de capacitação e assumissem cargos de direção nas unidades de atendimento ou Ciretrans. Com isso, procurou-se aproveitar os recursos humanos e o conhecimento técnico já existentes no órgão, o que foi importante, segundo a entrevistada, para conseguir o apoio dos funcionários ao processo de restruturação. Cursos de capacitação foram estendidos não só a funcionários do Detran-SP, mas também aos de credenciados (como os Centros de Formação de condutores, médicos e psicólogos - CFCs) e aos terceirizados responsáveis por serviços de atendimento, recepção e orientação.

Por último, um ponto ressaltado na entrevista com Daniel Annenberg, foi a preocupação com a regularização funcional dos colaboradores que tinham pendências relacionadas a estágio probatório, licença-prêmio e evolução funcional.

Contudo, percebemos que esses avanços demandaram tempo relativamente longo para materializar-se. Os novos funcionários (concursados) chegaram ao Detran-SP somente em 2014, cerca de três anos e meio depois do início da transição. Um dos fatores a contribuir para essa demora foi certamente o processo para tornar o Detran-SP uma autarquia - desde a criação do projeto até sua aprovação pelo Legislativo estadual - etapa que constituía pré-requisito para a contratação mediante concurso.

4.6 Instrumento 3: novas estruturas organizacionais
Do ponto de vista organizacional, o Detran-SP passou por uma alteração na sua forma jurídico-administrativa em 2013, ao transformar-se de órgão da administração direta (coordenadoria vinculada à Secretaria de Estado) em autarquia. Essa alteração Ihe conferiu personalidade jurídica de direito público e autonomia administrativa, financeira e patrimonial. Optava-se por um formato com mais autonomia, visando conferir ao órgão maior agilidade na resolução de seus problemas.

Essa mesma agilidade foi buscada também na descentralização, com a criação de 20 Superintendências Regionais com o objetivo de acompanhar, monitorar e dar suporte técnico principalmente nas áreas de Habilitação, Veículos e Administração, às Circunscrições Regionais de Trânsito (Ciretrans), nos municípios. Entretanto, por sua criação ter-se dado recentemente e sua implantação não ter sido concluída, uma avaliação completa dessas Superintendências fica prejudicada, sendo evidente apenas a orientação inicial escolhida e suas motivações. Concluir essa descentralização (regionalização) é um desafio importante. Entre outras questões, é importante obter maior uniformidade nos serviços e processos de trabalho, bem como na fiscalização dos serviços prestados.

Mudanças no organograma da instituição também se fizeram presentes, quando de sua transformação de coordenadoria em autarquia. A Lei Complementar 1.195/2013, que instituiu a autarquia, criou também uma presidência e uma vice-presidência, antes inexistentes (havia um coordenador e um coordenador adjunto). Juntamente com isso, foram instituídas seis diretorias setoriais: diretoria de habilitação, de veículos, de ad- 
ministração, de atendimento ao cidadão, de sistemas e de educação para o trânsito e fiscalização (cada uma delas por sua vez dividida em gerências, e estas em núcleos ou centros), além das 20 superintendências regionais já citadas.

Comparativamente à estrutura anterior à transformação em autarquia, que contava com oito diretorias (condutores, veículos, administração, educação para o trânsito, sistemas, sinalização e engenharia de tráfego, fiscalização de veículos e condutores, credenciamento), as mudanças mostram que algumas áreas passaram a ter mais relevância, ao passo que outras perderam visibilidade: a antiga diretoria de sinalização e engenharia de tráfego foi suprimida, tornando-se gerência; a de educação para o trânsito e a de fiscalização de veículos e condutores se fundiram em uma só. $E$, finalmente, a diretoria de atendimento ao cidadão, anteriormente inexistente, foi criada.

Outra questão que é importante destacar, ressaltada na entrevista com Daniel Annenberg, diz respeito à necessidade enfrentada pelo órgão de manter unidades enxutas, operando com número reduzido de funcionários concursados. Um dado que ajuda a interpretar essa questão é a relação entre as vagas criadas pela Lei Complementar, que criou a autarquia (2.200 vagas), e as disponibilizadas em concurso público (1.200), já abordada no item 4.5. Isso também teve efeitos sobre a nova estrutura organizacional do órgão, que precisou terceirizar parte de seu quadro: não só a segurança predial e a limpeza, mas também parte das atividades de recepção e atendimento ao público, passaram a ser feitas por pessoal terceirizado.

\subsection{Instrumento 4: controle de resultados}

Neste aspecto, embora tenha sido mantida uma lógica burocrática de controle a priori, à qual toda a administração pública brasileira está subordinada, a restruturação do Detran-SP envolveu algum deslocamento em direção a controles a posteriori que, apesar de não previstos na legislação, revelam uma preocupação com retroalimentação e redirecionamento de ações a partir da percepção da população atendida.

A implantação de um programa de bonificação por resultados, já mencionada no item 4.5, mostra uma preocupação em monitorar as atividades e incentivar atingimento de metas - em geral relacionadas a quantidades de serviços ou atendimentos realizados e tempos médios de espera por atendimento.

Por outro lado, como já citado no item 4.4, há também uma falta de informações gerenciais. Relatórios de monitoramento são feitos pelas unidades, mas não há um sistema mais completo, que abarque dados das diferentes unidades e permita uma visão sistêmica, gerando informação para decisões gerenciais e estratégicas, inclusive nas diretorias ou presidência. Pode-se dizer, assim, que há um controle incipiente, realizado nas unidades e focado no atendimento. Com isso, questões de eficácia e efetividade não apresentam um real monitoramento.

Além disso, tampouco se observam controles financeiros ou de custos para além daqueles permitidos pelos sistemas informatizados normalmente usados na administração pública paulista, como o Sistema Integrado de 
Administração Financeira para Estados e Municípios (Siafem) e o Sistema Integrado de Informações Físico-Financeiras (Siafísico). Caso houvesse controles ou sistemas do próprio órgão, seria possível efetuar meIhores análises quanto ao desempenho do Detran-SP e possibilidades de melhora de eficiência.

\section{Achados e considerações finais}

A discussão anterior, que mostra como o Detran-SP vem se desempenhando em seu processo de restruturação quanto a cada uma das categorias selecionadas (três princípios e quatro instrumentos da NAP), nos permite sintetizar os achados do estudo de caso no Quadro 2. A figura apresenta os principais avanços e lacunas em cada uma das sete categorias analisadas e as dificuldades que impediram o órgão de lograr avanços maiores.

Quadro 2. Síntese do estudo de caso: principais avanços, lacunas e entraves

\begin{tabular}{|c|c|c|c|}
\hline Dimensão & $\begin{array}{l}\text { Principais avanços } \\
\text { (o que foi feito) }\end{array}$ & $\begin{array}{l}\text { L } \quad \text { a } \quad c \quad \text { u } \quad n \quad \text { a } \quad s \\
\text { (o que não foi feito) }\end{array}$ & $\begin{array}{l}\text { E } \quad n \quad t \quad r \quad a \quad v \quad \text { e } \\
\text { (o que dificultou fazer) }\end{array}$ \\
\hline $\begin{array}{l}\text { Princípio 1: } \\
\text { foco no cidadão }\end{array}$ & $\begin{array}{l}\text { - Relacionamento proativo } \\
\text { com os cidadãos, envio de } \\
\text { comunicados } \\
\text { - Novo modelo de atendi- } \\
\text { mento pessoal } \\
\text { - Canais de atendimento } \\
\text { não presencial (telefone e } \\
\text { internet) }\end{array}$ & $\begin{array}{l}\text { - Não finalização da im- } \\
\text { plantação do novo modelo } \\
\text { de atendimento em todas } \\
\text { as unidades } \\
\text { - Pouca atenção dada à } \\
\text { participação da sociedade } \\
\text { no processo de restrutura- } \\
\text { ção, não tendo sido fomen- } \\
\text { tados canais de consulta }\end{array}$ & $\begin{array}{l}\text { - Forte controle procedimen- } \\
\text { tal (ex ante), e falta de fun- } \\
\text { cionários }\end{array}$ \\
\hline $\begin{array}{l}\text { Princípio 2: } \\
\text { eficiência }\end{array}$ & $\begin{array}{l}\text { - Negociação com fornece- } \\
\text { dores para redução de custos } \\
\text { dos contratos } \\
\text { - Racionalização de proces- } \\
\text { sos em nível micro } \\
\text { - Canais de atendimento não } \\
\text { presencial }\end{array}$ & $\begin{array}{l}\text { - O orçamento do órgão } \\
\text { aumentou } \\
\text { - Ausência de relatórios } \\
\text { gerenciais }\end{array}$ & $\begin{array}{l}\text { - Redução de custos nunca } \\
\text { foi um objeto explícito do } \\
\text { programa de restruturação, } \\
\text { que desde o princípio deu } \\
\text { mais ênfase à qualidade no } \\
\text { atendimento e à satisfação } \\
\text { do usuário }\end{array}$ \\
\hline $\begin{array}{l}\text { Princípio 3: } \\
\text { transparência }\end{array}$ & $\begin{array}{l}\text { - Criação de ouvidoria } \\
\text { - Acesso do cidadão à parte } \\
\text { de seus dados pela internet }\end{array}$ & $\begin{array}{l}\text { - Falta de integração de } \\
\text { sistemas que permita maior } \\
\text { disponibilização de dados } \\
\text { - Pouca exploração do sítio } \\
\text { eletrônico como canal de } \\
\text { transparência, privilegian- } \\
\text { do-se seu papel como canal } \\
\text { de servico }\end{array}$ & $\begin{array}{l}\text { - Baixa qualidade da maioria } \\
\text { dos sistemas em funciona- } \\
\text { mento }\end{array}$ \\
\hline
\end{tabular}


Dênis Alves Rodrigues - Martin Jayo

\begin{tabular}{|c|c|c|c|}
\hline $\begin{array}{l}\text { Instrumento 1: } \\
\text { TIC }\end{array}$ & $\begin{array}{l}\text { - Disponibilização de servi- } \\
\text { ços eletrônicos (internet). } \\
\text { - Desenvolvimento de siste- } \\
\text { mas para acesso pela web } \\
\text { (e-CNHsp) }\end{array}$ & $\begin{array}{l}\text { - Falta de integração dos } \\
\text { sistemas }\end{array}$ & $\begin{array}{l}\text { - Baixa qualidade dos siste- } \\
\text { mas legados } \\
\text { - Centralização do forne- } \\
\text { cimento de sistemas na } \\
\text { Prodesp, que não conseguiu } \\
\text { responder de maneira satis- } \\
\text { fatória }\end{array}$ \\
\hline $\begin{array}{l}\text { Instrumento 2: } \\
\text { gestão de pes- } \\
\text { soas }\end{array}$ & $\begin{array}{l}\text { - Regulamentação funcional } \\
\text { dos servidores } \\
\text { - Aumento salarial } \\
\text { - Cursos de capacitação/ } \\
\text { treinamento } \\
\text { - Aumento do quadro de } \\
\text { funcionários com criação de } \\
\text { carreiras específicas } \\
\text { - Programa de bonificação } \\
\text { por resultados }\end{array}$ & $\begin{array}{l}\text { - Não participação dos fun- } \\
\text { cionários no planejamento } \\
\text { tático e estratégico }\end{array}$ & $\begin{array}{l}\text { - Demora para criação de } \\
\text { novas carreiras } \\
\text { - Demora para abertura de } \\
\text { concurso público }\end{array}$ \\
\hline $\begin{array}{l}\text { Instrumento } 3 \text { : } \\
\text { novas estrutu- } \\
\text { ras organizacio- } \\
\text { nais }\end{array}$ & $\begin{array}{l}\text { - Transformação em au- } \\
\text { tarquia: maior autonomia e } \\
\text { agilidade } \\
\text { - Descentralização (criação } \\
\text { das Regionais) } \\
\text { - Terceirização de algumas } \\
\text { atividades } \\
\text { - Alteração do organograma, } \\
\text { com supressão e/ou fusão de } \\
\text { áreas e criação de diretoria } \\
\text { de Atendimento }\end{array}$ & $\begin{array}{l}\text { - Demora na implantação } \\
\text { das Regionais, o que difi- } \\
\text { culta a sua análise. } \\
\text { - Não definição clara do } \\
\text { papel das Regionais }\end{array}$ & $\begin{array}{l}\text { - Grande gama de atividades } \\
\text { diferentes sob a responsabili- } \\
\text { dade do órgão }\end{array}$ \\
\hline $\begin{array}{l}\text { Instrumento 4: } \\
\text { controle de re- } \\
\text { sultado }\end{array}$ & $\begin{array}{l}\text { - Monitoramento local da } \\
\text { qualidade do atendimento } \\
\text { nas unidades }\end{array}$ & $\begin{array}{l}\text { - Monitoramento apenas } \\
\text { local, ausência de visão } \\
\text { sistêmica } \\
\text { - Falta de monitoramento } \\
\text { em outras áreas (custos, } \\
\text { habilitação etc.) }\end{array}$ & $\begin{array}{l}\text { - Inexistência de relatórios/ } \\
\text { informações gerenciais impe- } \\
\text { de o monitoramento }\end{array}$ \\
\hline
\end{tabular}

Fonte: elaboração própria

Com isso, a principal contribuição do trabaIho foi ter levantado e discutido informações sobre como se deu a implantação de valores e práticas da NAP em um órgão público estadual relevante, com características de caso peculiar e revelador de um fenômeno novo: a implantação de reformas administrativas gerenciais em nível subnacional e intraorganizacional.

estudo traz uma contribuição para a prática gerencial ao servir como fonte de referên- 
cia para futuros projetos de restruturação no contexto da modernização administrativa em âmbito estadual ou municipal. Obviamente cada caso terá as suas particularidades, mas o exemplo de experiências relevantes, como a aqui analisada, pode servir de aprendizado ou referência a gestores públicos à frente de prováveis novos projetos de restruturação. A experiência do Detran-SP, aqui apresentada, pode ser entendida como um laboratório para melhor entendermos alguns dos desafios mais relevantes para tornar viável a modernização administrativa em organizações de nível subnacional.

Quanto às contribuições acadêmicas, o estudo de caso aqui apresentado não tem, evidentemente, a pretensão de preencher a escassez de pesquisas sobre reformas administrativas em âmbito subnacional e organizacional. Por outro lado, ele oferece um instrumento de análise - conjunto de categorias classificadas em princípios e instrumentos -, que poderá ser útil ao estudo de casos futuros, que, somando-se à análise aqui apresentada, venha a construir um conhecimento apurado sobre reforma administrativa em organizações públicas de nível subnacional.

Finalmente, um comentário com relação às limitações do estudo. Embora diferentes fontes de evidência empírica tenham sido utilizadas (observação participante, diferentes fontes documentais e entrevistas), não se pode negar a importância que as entrevistas tiveram para coleta e triangulação de dados do estudo de caso. Por esse motivo, o fato de as entrevistas terem se restringido a dois gestores responsáveis pela política implementada, com exclusão de outros grupos, como, por exemplo, funcionários do órgão, cidadãos usuários dos serviços ou mesmo atores políticos críticos à iniciativa, pode ser visto como um fator que limita os achados do estudo. Ao mesmo tempo, isso sugere um caminho para a ampliação do estudo, em uma fase subsequente do esforço de pesquisa.

\section{Referências}

Abrucio, F.L. (2007). Trajetória recente da gestão pública brasileira: um balanço crítico e a renovação da agenda de reformas. $R e-$ vista de Administração Pública, 41 (n. especial) 67-86.

Azoubel, F. (2006). Administração de departamentos de trânsito: desafios e soluções para a gestão pública. Recife: Livro Rápido.

Beatriz, M. S., \& Machado-da-Silva, Clóvis L. (1999). Mudança organizacional: a questão dos valores e dos interesses. Anais do 230 Encontro da Associação Nacional de Pós-graduação e Pesquisa em Administração, Foz do Iguaçu.

Bianco, M. F., Souza, E. M., \& Reis, A. M. S. (2014). A Nova Gestão Pública: um estudo do pró-gestão focado em dois projetos prioritários no Estado do Espírito Santo. Revista Gestão \& Planejamento, 15(1), 118-143.

Brasil (1995). Plano Diretor da Reforma do Aparelho do Estado. Brasília: Presidência da República.

Chaves, R. C., \& Marques, A. L. (2006). Mudança organizacional no setor público: um estudo sobre o impacto das mudanças instituídas pelo Governo do Estado de Minas 
Gerais numa instituição pública estadual. Anais do 300 Encontro da Associação Nacional de Pós-graduação e Pesquisa em Administração, Salvador.

Colombo, C. (2006). Innovación democrática y TIC, ¿hacia una democracia participativa? Revista de Internet, Derecho y Política, 3, 28-40.

Cunha, M. A. V. C., \& Miranda, P. R. (2013). $O$ uso de TIC pelos Governos: uma proposta de agenda de pesquisa a partir da produção acadêmica e da prática nacional. Organizações \& Sociedade, 20 (66): 543-566.

Denhardt, R. (2012) Teorias da Administração Pública. São Paulo: Cengage Learning.

Dunleavy, O, Margetts, H., Bastow, S., \& Tinkler, J. (2006). New Public Management is dead - long live digital era governance. Journal of Public Administration Research and Theory, 16 (3), 467-494.

Farah, M. F. S. (1997). Gestão pública e cidadania: iniciativas inovadoras na administração subnacional no Brasil. Revista de Administração Pública, 31 (4): 126-156.

Farah, M. F. S. (2000). Governo local, políticas públicas e novas formas de gestão pública no Brasil. Organizações \& Sociedade, 6 (17): 59-86.

Fernandes, A. S. A, Moraes, D. B., \& Nascimento, A. M. (2015). Reformas administrativas nos estados brasileiros: o caso da reforma administrativa do estado do Piauí. Cadernos Gestão Pública e Cidadania, São Paulo, 20 (67): 194-213
Fresneda, P. S. V. (1998). Transformando organizações públicas: a tecnologia da informação como fator propulsor de mudanças. Revista do Serviço Público, 49 (1): 71-90.

Hood, C., \& Peters, G. (2004). The middle aging of new public management: into the age of paradox? Journal of Public Administration Research and Theory, (14) 3: 267-282.

Kettl, D. F. (2006). A revolução global: reforma da administração do setor público. In: Bresser Pereira, L. C; Spink, P.K. (Org.). Reforma do Estado e Administração Pública Gerencial. Rio de Janeiro: FGV, p. 75-121.

Lima, P. D. B. (2007). Excelência em gestão pública: a trajetória e a estratégia do Gespública. Rio de Janeiro: Qualitymark.

Lindblom, C. E. (2010). Muddling Trough 1: a ciência da decisão incremental. In: Heidemann, F. G., \& Salm, J. F. (Org.). Políticas públicas e desenvolvimento: bases epistemológicas e modelos de análise. Brasília: UNB.

Mariotto, F. L., Zanni, P. P., \& Moraes, G. H. S. M. (2014). What is the use of a single-case study in management research? Revista de Administração de Empresas, São Paulo, 54, 358-369.

Mongkol, K. (2011). The Critical Review of New Public Management Model and its Criticisms. Research Journal of Business Management, 5: 35-43.

O'Donnell, G. (2011). Democracia, agência e estado. Teoria com intenção comparativa. São Paulo. Paz e Terra.

Osborne, D., \& Gaebler, T. (1998). Reinven- 
tando o Governo: como o espírito empreendedor está transformando o setor público. Brasília: MH Comunicação.

Paula, A. P. P.de (2005). Administração pública brasileira: entre o gerencialismo e a gestão social. Revista de Administração de Empresas, 45 (1): 36-49.

Pollitt, C., \& Bouckaert, G. (2011). Public Management Reform: a Comparative Analysis - New Public Management, governance, and the neo-Weberian state. Oxford: Oxford University Press.

Prado, M. M., \& Chasin, A. C. M. (2011). How innovative was the Poupatempo experience in Brazil? Institutional bypass and a new form of institutional change. Brazilian Political Science Review, 5 (1): 11-34.

Przeworski. A. (2006). Sobre o desenho do Estado: uma perspectiva agente $\mathrm{x}$ principal. In: Bresser Pereira, L. C., \& Spink, P. K. (Org.). Reforma do Estado e Administração Pública Gerencial. Rio de Janeiro: FGV, 2006. pp. 39-73.

Queiroz, R. G. M., \& Ckagnazaroff, I. B. (2010). Inovação no setor público: uma análise do Choque de Gestão (2003-10) sob a ótica dos servidores e dos preceitos teóricos relacionados à inovação no setor público. Revista de Administração Pública, 44 (3) 679-705.
Sano, H., \& Abrucio, F. L. (2008). Promessas e resultados da Nova Gestão Pública no Brasil: o caso das organizações sociais na saúde em São Paulo. Revista de Administração de Empresas, 48 (3): 64-80.

Saur, R. A. C. (2001). A tecnologia da informação na reforma do Estado: uma reflexão sobre os dilemas e perspectivas para as grandes empresas de processamento de dados da área pública. Brasília: ENAP (Texto para discussão, 6).

Seade (2014). Desenvolvimento e aplicação de metodologia de avaliação de impactos de Programas Públicos, março de 2014: análise dos resultados da primeira tomada da pesquisa com usuários do Detran-SP, com base em uma pesquisa efetuada. São Paulo: Fundação Serviço Estadual de Análise de Dados.

Wood Jr, T. (1992). Mudança organizacional: uma abordagem preliminar. Revista de $A d$ ministração de Empresas, 32 (3) 74-87.

Xavier, R. O., \& Dias, S. M. R. C. (2002). Avaliando a mudança: a percepção dos gerentes sobre o comportamento organizacional após a privatização. Anais do 260 Encontro da Associação Nacional de Pós-graduação e Pesquisa em Administração, Salvador.

Yin, Robert K. (1994). Case study research: design and methods. New York: Sage. 